\title{
ASSESSMENT OF NET PRIMARY PRODUCTIVITY OVER INDIA USING INDIAN GEOSTATIONARY SATELLITE (INSAT-3A) DATA
}

\author{
Sheshakumar Goroshi†, Raghavendra P Singh, Rohit Pradhan and Jai Singh Parihar \\ (†sheshakumarg@sac.isro.gov.in)
}

Space Applications Centre (ISRO), Ahmedabad, India 380015

KEYWORDS: INSAT-3A, NPP, Productivity, CASA, Ecosystem

\begin{abstract}
Polar orbiting satellites (MODIS and SPOT) have been commonly used to measure terrestrial Net Primary Productivity (NPP) at regional/global scale. Charge Coupled Device (CCD) instrument on geostationary INSAT-3A platform provides a unique opportunity for continuous monitoring of ecosystem pattern and process study. An improved Carnegie-Ames-Stanford Approach (iCASA) model is one of the most expedient and precise ecosystem models to estimate terrestrial NPP. In this paper, an assessment of terrestrial NPP over India was carried out using the $i$ CASA ecosystem model based on the INSAT CCD derived Normalized Difference Vegetation Index (NDVI) with multisource meteorological data for the year 2009. NPP estimated from the INSAT CCD followed the characteristic growth profile of most of the vegetation types in the country. NPP attained maximum during August and September, while minimum in April. Annual NPP for different vegetation types varied from $1104.55 \mathrm{gC} \mathrm{m}^{-2}$ year-1 $^{-1}$ (evergreen broadleaf forest) to $231.9 \mathrm{gC} \mathrm{m}^{-2}$ year ${ }^{-1}$ (grassland) with an average NPP of $590 \mathrm{gC} \mathrm{m}^{-2}$ year-1. We estimated $1.9 \mathrm{PgC}$ of net carbon fixation over Indian landmass in 2009. Biome level comparison between INSAT derived NPP and MODIS NPP indicated a good agreement with the Willmott's index of agreement (d) ranging from 0.61 (Mixed forest) to 0.99 (Open Shrubland). Our findings are consistent with the earlier NPP studies in India and indicate that INSAT derived NPP has the capability to detect spatial and temporal variability of terrestrial NPP over a wide range of terrestrial ecosystems in India. Thus INSAT-3A data can be used as one of the potential satellite data source for accurate biome level carbon estimation in India.
\end{abstract}

\section{INTRODUCTION}

Net primary productivity (NPP) is the dry matter produced by the green vegetation per unit area and per unit time (Peng et al. 2000). Regular monitoring of NPP gives useful information for management of natural resources (Liu et al. 1997) and amount of $\mathrm{CO}_{2}$ removed from the atmosphere through photosynthesis and respiration (Bonan 2008; Grosso et al. 2008). Due to dynamic environmental conditions, NPP varies with time and space (Cao et al. 2004). However, to monitor this accurately and to understand its role in carbon dynamics within the atmosphere-vegetation-soil continuum, we require an accurate, simple and dynamic approach.

A number of statistical (Leith, 1975), parametric (Law and Waring, 1994) and process based models (Bonan 1995) have been developed to monitor terrestrial NPP and its interaction with regional climatic conditions. Over decades, several statistical models are developed based on correlating field NPP with mean annual temperature, precipitation and evapotranspiration (Lieth 1975) but they do not capture temporal lags in vegetation response to climate (Goward and Prince, 1995). The parametric models estimate NPP based on (Kumar and Monteith 1981) radiation efficiency concept to decompose NPP into independent parameters such as insolation, light use efficiency and conversion efficiency of absorbed radiation in to dry matter (Ruimy et al., 1994). Liu et al., (1997) reported that process based models are reliable, sophisticated and useful for revealing dry matter production, plant-environment interaction and for analyzing the response of vegetation to varying climate. Ruimy et al., (1994) reported that these models are not satisfactory, at present times, for performing the global analysis due to lack of ecosystem specific inputs for different landcover types on a global scale. Remote sensing technology provides an ideal vantage point for getting a large synoptic view of land surface and facilitates mapping at various scales based on their sensing platform. Studies (Sellers 1985; Running et al., 1989) in ecological modeling have linked process based models with remotely sensed observation for assessing regional to global scale patterns in ecosystem production.

Ruimy et al. (1999) classified these models broadly as Production Efficiency Models (CASA, GLO-PEM, HRBM and TURC) and Canopy Photosynthesis Models (BIOME3, CARAIB, FBM, HYBRID, KGBM, PLAI, SIB2 and SILVAN) based on the method employed to model the absorption of solar radiation and its conversion into dry matter. PEMs are less complex stand level process based models that estimate terrestrial NPP based on conversion efficiency approach (Kumar and Monteith, 1981) with very less inputs, mainly driven by satellite data. CPMs are very complex and require large number of inputs to derive different processes of terrestrial vegetation productivity. Nevertheless, PEM models are widely used to assess spatio-temporal variations in terrestrial NPP and its response to global climatic phenomenon like warming, ENSO events and regional climate variability. Such studies require precise input 
parameters. Absorbed Photosynthetically Active Radiation (APAR) and Light Use Efficiency (LUE) are key input parameters for PEM models. Although spatiotemporal variation in APAR can be measured and mapped regularly through satellite remote sensing technique (Sellers et al., 1992), no such satellite-based measurements can yet be made for photosynthetic efficiency (Boegh et al., 2002). LUE varies spatially as well as temporally between vegetation types and locations due to their respiration cost and suboptimal climatic conditions (Gower et al., 1999). As a result producing representative LUE values for regions with extensive vegetation cover is very difficult because native vegetation types and crops generally have different LUE values (Gower et al., 1999), creating spatial heterogeneity not measured through remotely sensed reflectance measurements. Details of widely used approach to integrate information about ecosystem types and influence of regional environmental conditions (temperature and available soil moisture status on LUE calculations) are mentioned in Ruimy et al. (1994). Carnegie-Ames-Stanford Approach (CASA) is an extensively used, satellite data driven ecosystem model, offers a unique opportunity for simulating terrestrial NPP at larger spatial scale with less input data. The model controls photosynthetic efficiency in response to spatiotemporally varying stress constraints resulting from temperature and water. One of the largest sources of error in their study was "maximum LUE". They used sole LUE value $\left(0.389 \mathrm{gC} \mathrm{MJ}^{-1}\right)$ for different vegetation types due to the very small data set $(n<15)$ of measured NPP in different vegetation types that existed worldwide at the time, Potter et al. (1993) essentially had to assume a globally uniform LUE (0.389 $\mathrm{gC} \mathrm{MJ})$ for all vegetation types. A comparative analysis (Hicke 2006) using two data sets (National Centres for Environment Predications and Goddard Institute for Space Science) and CASA model by allocating exclusive maximum LUE values (0.46 to $0.50 \mathrm{gC} \mathrm{MJ}^{-1}$ ) for different landcover types, found varying response of LUE with native meteorological, soil, topography and physiological conditions. Another limitation of the CASA model (Potter et al. 1993) is that, they estimate moisture stress factor at each grid cell using monthly temperature and precipitation data in amalgamation with several soil parameters like field moisture capacity, wilting coefficient, percentage of sand and clay particles and depth of soil. However, this moisture submodel is extremely complex, requires several soil attributes, which are generally obtained from a soil map whose accuracy is very low when compared on global scale. Thus, Yu et al (2009) improved the earlier CASA (Potter et al., 1993) model in two aspects without changing their original plant physiological and ecological basis for estimating NPP. First calculated maximum LUE ( $\varepsilon_{\max }$ ) values for different vegetation types using observed NPP and estimated NPP. Secondly, simplified the earlier soil moisture submodel by replacing several soil attributes with a monthly meteorological parameters (solar radiation, temperature and precipitation) in the existing regional evapotranspiration model to determine moisture stress coefficient. In the present study we estimating terrestrial NPP over India using improved CASA model and geostationary INSAT-3A satellite data for the period 2009.

\section{STUDY AREA AND INSTRUMENT}

The study area is India with a total geographical area of 329 million hectares situated in the tropics between $7^{\circ} \mathrm{N}$ and $40^{\circ} \mathrm{N}$ and between $68^{\circ} \mathrm{E}$ and $100^{\circ} \mathrm{E}$. The country is known for its diverse vegetation ecosystems and biodiversity (Fig. 1). The region is predominantly covered by evergreen needleleaf forest (ENF), evergreen broadleaf forest (EBF), deciduous broadleaf forest (DBF), mixed forest (MF), closed shrublands (CSH), open shrublands (OSH), woody savannas (WSA), savanna (SA), grasslands (GRA), wetlands (WET), croplands (CRO), croplands/natural vegetation mosaic (CRO/NAT. Mosaic), snow and ice, barren and sparsely vegetation (BAR/SPARSLY VEG.) and water bodies. The region experiences four climatically different seasons in a year: southwest summer monsoon (JuneAugust), northeast winter monsoon (December to February), spring or pre-monsoon (March-May) and autumn post-monsoon (September-November) Inter monsoonal periods. The southwest monsoon is essentially warm and humid, and the rainfall received during this period accounts for $80 \%$ of the total annual rainfall of the country. Northeast monsoon is cold and dry; however, the southeastern parts of the country receive significant rainfall during this period. The two inter-monsoonal periods are mostly dry and moderately warm.

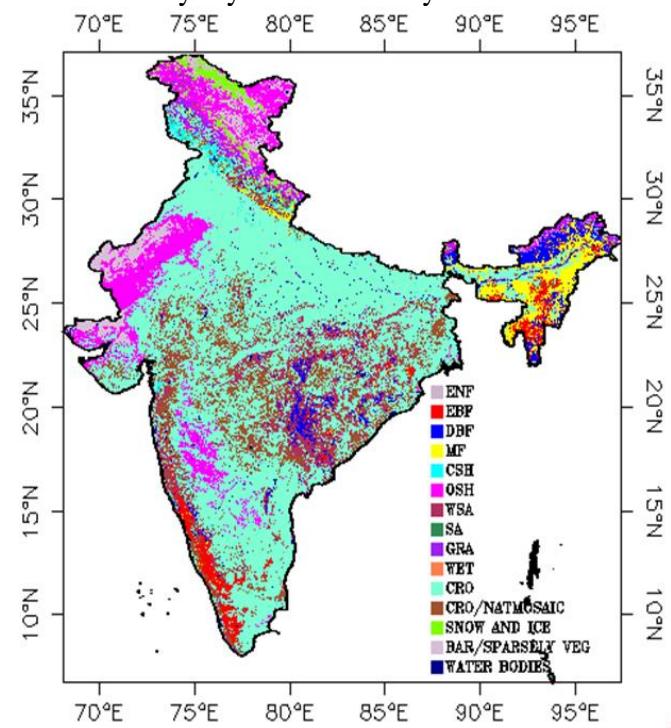

Figure. 1 Land cover map (IGBP Version 2.0) depicting different vegetation types in India.

INSAT-3A is a multipurpose satellite built by Indian Space Research Organisation (ISRO) and it was launched from European Ariane-5G Launch Vehicle into a Geosynchronous Transfer Orbit (GTO) in April 2003. It is third satellite in INSAT-3 series after INSAT-3B \& INSAT-3C. This satellite was basically designed for telecommunications, television broadcasting, meteorological and search \& rescue services. It carries twenty four transponders - twelve operating in the normal 
$\mathrm{C}$-band frequency, six in Extended $\mathrm{C}$-band and six in $\mathrm{Ku}$ band. Nine of the twelve normal C-band transponders provide expanded coverage and the remaining three have India coverage beam. All the extended C-band as well as the Ku-band transponders has India coverage beams. INSAT-3A also carries a Ku-band beacon.

For meteorological observation, INSAT-3A carries a three channel Very High Resolution Radiometer (VHRR) with $2 \mathrm{~km}$ resolution in the visible band and $8 \mathrm{~km}$ resolution in thermal infrared and water vapour bands. In addition, INSAT-3A carries a Charge Coupled Device (CCD) camera which operates in the visible and short wave infrared bands providing a spatial resolution of 1 $\mathrm{km}$ (Table 1).

Table 1 Details of INSAT 3A CCD sensor

\begin{tabular}{lll}
\hline Channels & $\begin{array}{l}\text { Wavelength } \\
\text { range }(\mu \mathrm{m})\end{array}$ & $\begin{array}{l}\text { Spatial } \\
\text { resolution } \\
(\mathrm{km})\end{array}$ \\
\hline Visible & $0.63-0.69$ & $1 \mathrm{~km}$ \\
NIR & $0.77-0.89$ & $1 \mathrm{~km}$ \\
SWIR & $1.55-1.69$ & $1 \mathrm{~km}$ \\
FOV & $\begin{array}{l}10^{\circ} \times 10^{\circ}(\text { Normal } \\
\text { frame }),\end{array}$ \\
& $6250 \times 6250 \mathrm{~km}^{2}$ \\
& $0500 \mathrm{GMT}(1030$ \\
Time of overpass & \\
considered & LMT) \\
\hline
\end{tabular}

GMT: Greenwich Mean Time; LMT: Local Mean Time.

The CCD derived NDVI has been the focus of several studies in India (Bhattacharya et al., 2010, Nigam et al., 2013). In the present study, CCD derived NDVI was used to generate monthly terrestrial Net Primary Productivity (NPP) over India for the period 2009.

\section{DATA USED}

Ten day composite Normalized Difference Vegetative Index (NDVI) data for the study period (2009) was obtained from Meteorology Oceanography Satellite Data Archive Centre (MOSDAC), Space Applications Centre, India. The data was used in the present study to derive biome specific fraction of Absorbed Photosynthetically Active Radiation (fPAR). Spatial distribution of diverse vegetations types and its unique response to local conditions is among the vital key parameters in the improved CASA ecosystem model. An extensively validated (Hansen and Reed 2000) global landcover data with $1 \mathrm{~km}$ spatial resolution created by the U.S. Geological Survey (USGS), the University of NebraskaLincoln (UNL), and the European Commission's Joint Research Centre (JRC) for environmental research and modeling studies was acquired from International Geosphere-Biosphere Programme Data and Information System (IGBP-DIS). This was used to derive fraction of Photosynthetically Active Radiation (fPAR) and allocating biome specific maximum Light Use Efficiency (LUE) for different vegetation types in the study region. Classification scheme adopted in this landcover was based on biome specific phenological events; estimated using monthly maximum Advanced Very High Resolution Radiometer (AVHRR) derived NDVI data.
This scheme categorizes the entire study region into 17 vegetation classes (Fig. 1).

We utilized meteorological data (mean temperature, precipitation and incident solar radiation) to derive temperature and moisture stress coefficients. Mean monthly temperature and cumulated monthly precipitation with $0.5^{\circ}$ spatial resolution were acquired from Climate Research Unit (CRU) at University of East Anglia (UEA). Downward monthly shortwave radiation with $1 / 2 \times 2 / 3^{\circ}$ spatial resolution was obtained from Modern-Era Retrospective Reanalysis for Research and Applications (MERRA). Utility of model derived variables can only be used for further study if they are properly validated. Moderate Resolution Imaging Sensor (MODIS) derived NPP product, derived using extensive field NPP measurements, eddy flux tower data, multisensor satellite data and process based model offer such invaluable opportunities to evaluate INSAT derived NPP as well as iCASA model performance because MODIS products are already extensively validated across the world using different data sources. In the present study MODIS NPP data obtained for the study period was used in the study to validate INSAT derived NPP over wide range of vegetation types in India.

Light Use Efficiency (LUE) is key input parameter in Production Efficiency Model (PEM). LUE varies between vegetation types due to their respiration cost and suboptimal climatic conditions. As a result producing biome specific LUE values for extensive vegetation cover is very difficult due to heterogeneity of native vegetation types (Gower et al., 1999). Yu et al. (2009) were derived biome specific LUE values for different vegetation types in East Asia region $\left(10-70^{\circ} \mathrm{N}, 70-170^{\circ} \mathrm{E}\right)$ through principle of minimal error approach between estimated NPP and observed NPP (field measurement data). Therefore, in this analysis, we used $\mathrm{Yu}$ et al. (2009) derived biome specific LUE values to estimate precise NPP for various vegetation types in Indian subcontinent.

Monthly NDVI and fPAR data from Advanced Very High Resolution Radiometer (AVHRR) sensors onboard series of National Oceanic and Atmospheric Administration (NOAA) satellites was acquired from 1981 to 2006. This data was used here to derive landcover specific $\mathrm{NDVI}_{\max }, \mathrm{NDVI}_{\min }, \mathrm{fPAR}_{\max }, \mathrm{PPAR}_{\min }$ (Table 1) which are important parameter for generating biome wise accurate fPAR values in the country.

Table 2.Biome specific minimum and maximum NDVI and fPAR values in Indian region

\begin{tabular}{|c|c|c|c|c|c|}
\hline IGBP & LULC & NDVI & NDVI & fPAR & fPAR \\
\hline Code & Type & Min. & Max. & Min & Max. \\
\hline 01 & ENF & 0.090 & 0.871 & 0.301 & 0.843 \\
\hline 02 & EBF & 0.014 & 0.944 & 0.564 & 0.906 \\
\hline 03 & DNF & 0.021 & 0.890 & 0.529 & 0.913 \\
\hline 04 & DBF & 0.131 & 0.870 & 0.532 & 0.916 \\
\hline 05 & $\mathrm{MF}$ & 0.035 & 0.896 & 0.620 & 0.896 \\
\hline 06 & $\mathrm{CS}$ & 0.043 & 0.810 & 0.469 & 0.858 \\
\hline 07 & OS & 0.044 & 0.798 & 0.133 & 0.625 \\
\hline 08 & WS & 0.093 & 0.841 & 0.427 & 0.913 \\
\hline 09 & SA & 0.110 & 0.784 & 0.204 & 0.742 \\
\hline 10 & GRA & 0.016 & 0.655 & 0.226 & 0.783 \\
\hline 11 & PW & 0.011 & 0.891 & 0.145 & 0.776 \\
\hline
\end{tabular}




\begin{tabular}{llllll}
12 & CRO & 0.082 & 0.827 & 0.273 & 0.834 \\
14 & CRO/ & 0.041 & 0.870 & 0.269 & 0.795 \\
& NVM & & & & \\
\hline
\end{tabular}

\section{MODEL DESCRIPTION AND STRUCTURE}

Modeling of NPP was carried out using modified Carnegie-Ames-Stanford Approach (CASA). Detailed procedure for the estimation of NPP is shown in flow chart (Fig. 2) and explained in subsequent steps.

3.1 Model description: NPP in the present study was estimated using improved CASA ecosystem model (Yu et al., 2009). The model estimate NPP as a product of absorbed photosynthetically active radiation (APAR) and maximum energy conversion efficiency ( $\varepsilon_{\max }$ ) of the vegetation. The model can be expressed as in equation (1) (Potter et al. 1993):

$$
\mathrm{NPP}=\mathrm{APAR} \times \varepsilon_{\text {max }}
$$

where NPP represents the net primary productivity $(\mathrm{gC}$ $\mathrm{m}^{-2} \mathrm{month}^{-1}$ ); APAR is absorbed photosynthetically active radiation $\left(\mathrm{MJm}^{-2}\right.$ month $\left.^{-1}\right)$ and $\varepsilon_{\max }$ is maximum energy conversion efficiency of the vegetation $\left(\mathrm{gC} \mathrm{MJ}^{-1}\right)$. A structure diagram of the improved CASA algorithm is shown in Fig. 2.

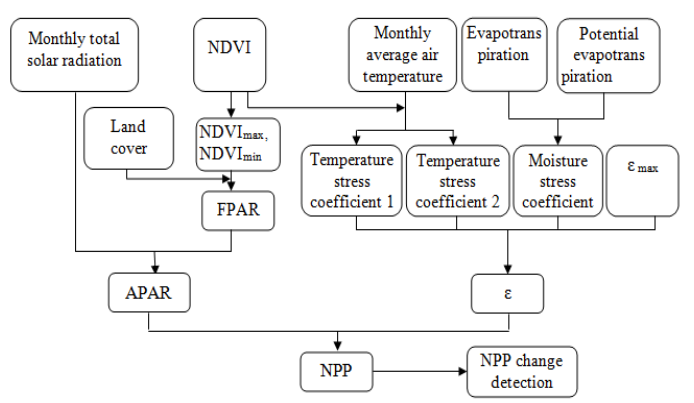

Figure 2. Framework of modified CASA ecosystem model depicting the modeling steps, the input requirements and their spatio-temporal resolutions.

\subsection{Comparison of INSAT NPP with MODIS NPP}

INSAT derived NPP values were compared with MODIS NPP using two important statistical measures: the root mean square error (RMSE) and Willmott's index of agreement for model validation (Willmott, 1981 and 1982). The Willmott's index of agreement (d) is defined as

$$
\mathrm{d}=1-\frac{\sum_{i=1}^{n}\left(\mathrm{O}_{\mathrm{i}}-\mathrm{P}_{\mathrm{i}}\right)^{2}}{\sum_{i=1}^{n}\left(\left|\mathrm{O}_{\mathrm{i}}-\overline{\mathrm{O}}\right|+\left|\mathrm{P}_{\mathrm{i}}-\overline{\mathrm{O}}\right|\right)^{2}}
$$

Where $\mathrm{O}_{i}$ is observed value (tower NPP), $\mathrm{P}_{\mathrm{i}}$ is the estimated value (INSAT NPP), $\overline{\mathrm{O}}$ and $\overline{\mathrm{P}}$ are mean of the observed and estimated NPP values. A nondimensional measure (d) that ranges from 0 to 1 , wherein $\mathrm{d}$ is equal to 1 when two data sets are in ideal agreement.

\section{Result and Discussion}

4.1 Spatial and Temporal variability of NPP: Mean monthly NPP over Indian subcontinent for the study period 2009 is shown in Figs. 3\&4. Two distinct seasons can apparently see from the figures. The winter (January to March) and monsoon (July to October) seasons. It was observed during January that due to dry winter spell in the entire country, vegetation was stopped growing in most parts of the country and NPP was reached to very low. In parts of the Western India especially at desert regions and non vegetated areas the NPP was even went up to zero. The mean NPP for the entire country during this month was estimated to be $43.42 \pm 20.77 \mathrm{gCm}^{-2}$ month $^{-1}($ mean \pm SD), which was 12 percent lesser than mean monthly NPP $\left(49.15 \pm 10.46 \mathrm{gCm}^{-2}\right.$ month $\left.^{-1}\right)$ of the country. Low NPP in the month was mainly due to the low contribution of NPP by deciduous and evergreen forest situated in Western-Ghats and North-Eastern regions. In February month mean NPP $(45.96 \pm 20.92$ $\mathrm{gCm}^{-2}$ month $^{-1}$ ) was increased considerably by 6 percent than mean NPP of previous month. Substantial increase of NPP in the month was basically due to the coincidence of peak growth stages of the major crops especially in Indo- Gangetic plains and Punjab regions. As the crops achieved maturity and senescence stage during the end of the winter season (March), mean monthly NPP $\left(39.61 \pm 19.58 \mathrm{gCm}^{-2}\right.$ month $\left.^{-1}\right)$ was reduced strongly by 13 per cent than previous month and 20 per cent as compared to the mean monthly NPP of the country. In April, mean monthly NPP of the country $(36.06 \pm 20.86$ $\mathrm{gCm}^{-2}$ month $^{-1}$ ) was reduced drastically with attaining annual lowest mean monthly NPP value. The value was about 9 and 27 per cent lower than mean monthly NPP of previous month and mean monthly NPP of the country. From May month, increasing pattern of NPP was observed due to onset of flushing in forest regions of Sothern and South-Eastern states of the country. Approximately 10 per cent more NPP was observed in May $\left(39.93 \pm 23.45 \mathrm{gCm}^{-2}\right.$ month $\left.^{-1}\right)$ as compared to the mean NPP of the previous month. But still it was 19 per cent lower than the mean monthly NPP of the country. There was large change in NPP value $\left(53.71 \pm 23.45 \mathrm{gCm}^{-}\right.$ ${ }_{2}$ month $^{-1}$ ) was observed in June due to the onset of South-West monsoon. About 26 per cent more NPP was January

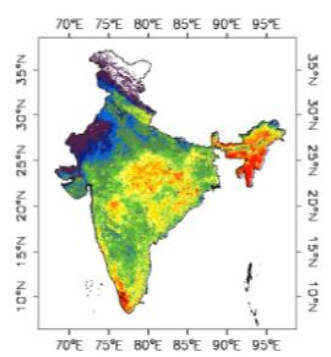

March February

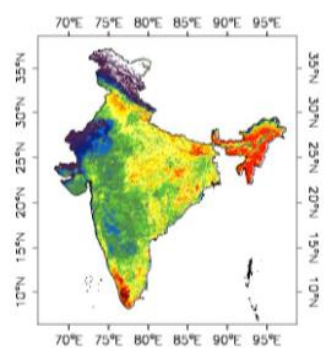

April 


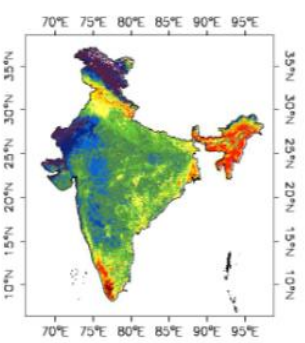

May

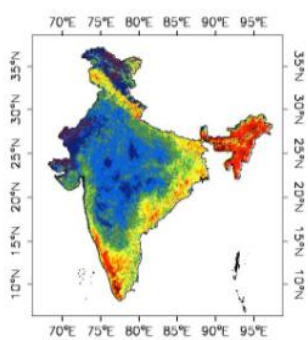

July

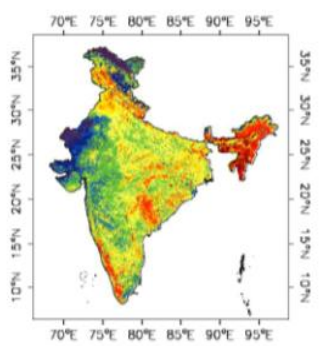

September

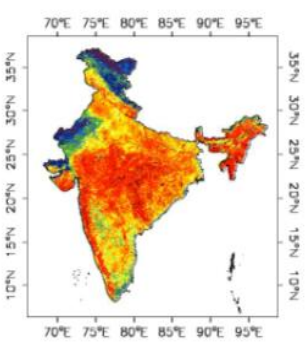

November

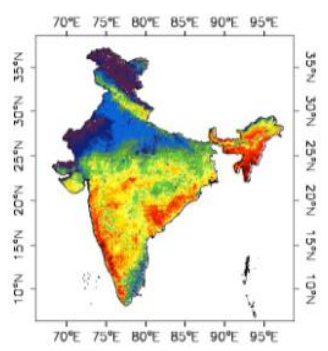

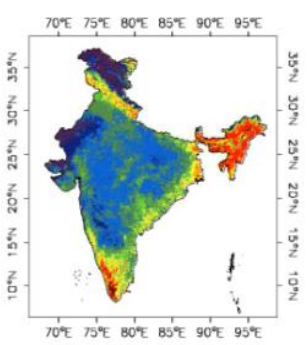

June

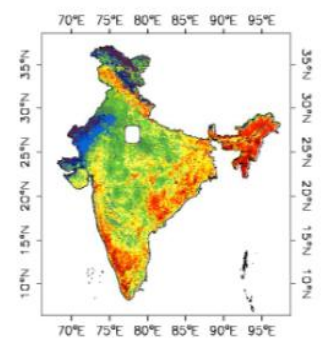

August

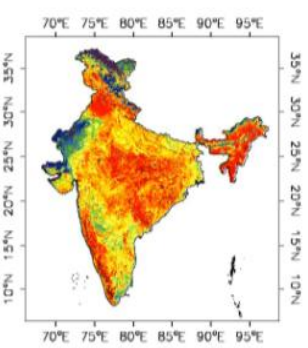

October

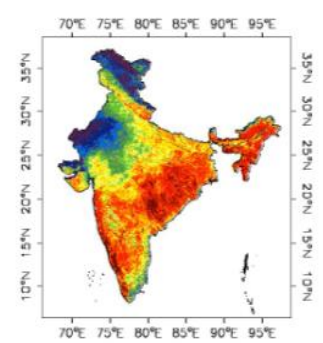

December

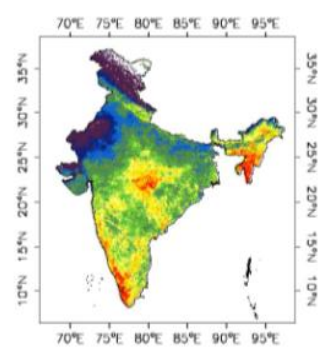

Net Primary Productivity $\left(\mathrm{g} \mathrm{C} \mathrm{m}^{-2}\right.$ month $\left.^{-1}\right)$

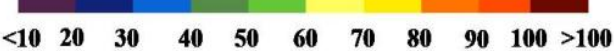

Figure 3 Spatial distribtion of Monthly NPP in India estimated using INSAT 3A CCD data

observed in June as compared to the NPP of May month. It was 10 per cent higher than the mean monthly NPP of the country. In subsequent month (July), appearance of unexpected dip was due to cloudy condition during satellite pass. As the development in monsoon, NPP in the entire region was substantially increased especially in

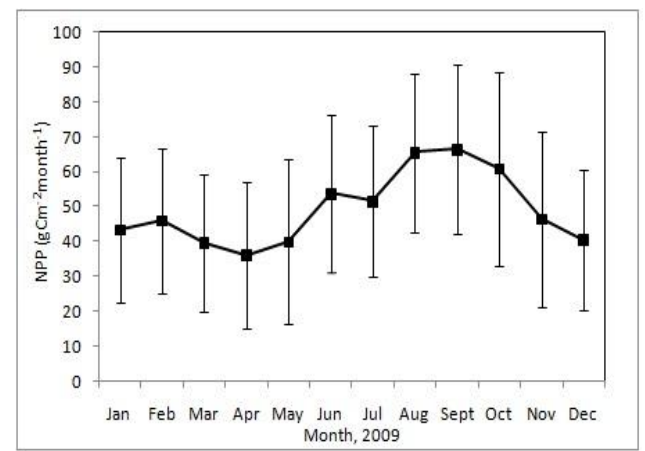

Figure 4 Monthly change of mean NPP over Indian subcontinent

agricultural and grassland regions. Mean monthly NPP in August $\left(65.43 \pm 22.67 \mathrm{gCm}^{-2}\right.$ month $\left.^{-1}\right)$ was reached 33 per cent more NPP than mean monthly NPP of the country. In September, mean monthly NPP was reached at its peak NPP $\left(66.47 \pm 24.43 \mathrm{gCm}^{-2}\right.$ month $\left.^{-1}\right)$ value with 36 per cent more NPP as compared to the mean NPP of the country. As the south west monsoon widraw, NPP was started declining. Mean monthly NPP in October was $\left(53.71 \pm 23.45 \mathrm{gCm}^{-2}\right.$ month $\left.^{-1}\right)$ reduced by 10 per cent as compared to the previous month and was just 20 per cent higher than mean monthly NPP of the country. During November, NPP was declined drastically $(46.43 \pm 25.08$ $\mathrm{gCm}^{-2}$ month $^{-1}$ ) by 24 per cent as compared to the previous month and 5 per cent lower than the mean monthly NPP of the country. That decreasing pattern was continued to December with mean NPP of $40.39 \pm 34.10$ $\mathrm{gCm}^{-2}$ month ${ }^{-1}$, which was 13 per cent lower than NPP of revious month and 18 per cent lower NPP value than mean NPP value of the country.

4.2 Seasonal change of NPP in different vegetation: Seasonal change of NPP for each vegetation type in India is shown in Figure 5. It can be observed from the figures that seasonal change of NPP decreases from evergreen broadleaf forest (EBF), deciduous broadleaf forest (DBF) and croplands to grasslands. Seasonal change of EBF was the lowest among all the vegetation types. The forest was achieved peak growth in winter as well as in monsoon season with a mean monthly NPP of $100 \mathrm{gCm}^{-2}$ month $^{-1}$ and $110 \mathrm{gCm}^{-2} \mathrm{month}^{-1}$, respectively. As for $\mathrm{DBF}$, maximum NPP was appeared in September $\left(92 \mathrm{gCm}^{-2}\right.$ month $\left.^{-1}\right)$. However, for croplands, there were two NPP climaxes in some regions (Indo-Gangetic and Punjab) were observed due to double cropping pattern. The first climax was appeared in February $\left(63 \mathrm{gCm}^{-2}\right.$ month $\left.{ }^{-1}\right)$ and second was in September $\left(80 \mathrm{gCm}^{-2} \mathrm{month}^{-1}\right)$.

NPP of the first climax was relatively lower than the second climax because first crop was wheat and second was rice, however the productivity of wheat generally lower that of rice. Grasslands showed the lowest NPP among all the vegetation types. Grasslands were started flushing in June and attained maximum growth in September $\left(45 \mathrm{gCm}^{-2}\right.$ month $\left.^{-1}\right)$. NPP of grasses in arid regions (parts of Rajasthan and Gujarat) was very low as compared to the NPP of grasses situated in wet or moist regions due to growth of grasses in arid regions were limited by moisture condition. 


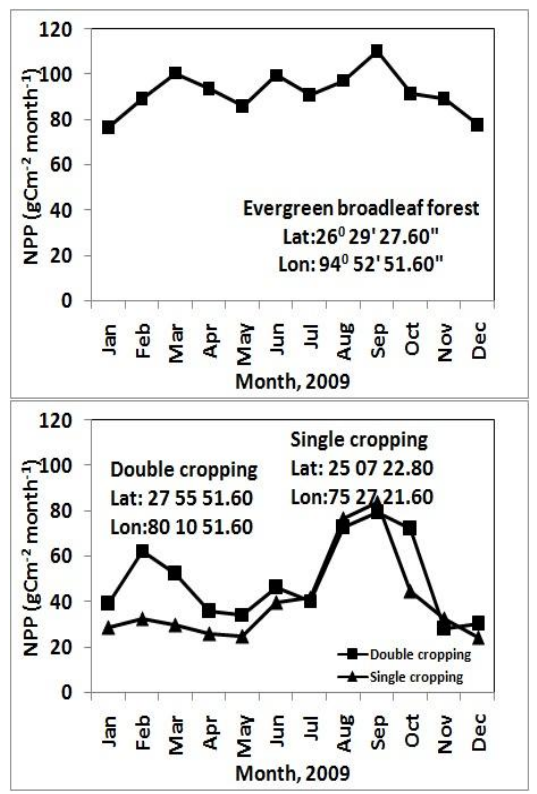

Figure 5 Seasonal change of NPP

Figure 6 depicts spatial distribution map of annual NPP in India. NPP derived from INSAT CCD using improved CASA model showed maximum $\left(>1200 \mathrm{gCm}^{-2}\right.$ year $\left.^{-1}\right)$ NPP in evergreen broadleaf forest of North-East and Western-Ghats regions, whereas the lowest NPP $(<100$ $\mathrm{gCm}^{-2}$ year $\left.^{-1}\right)$ was observed in arid regions of Rajasthan.

Net carbon fixation over Indian landmass during 2009 was estimated about $1.9 \mathrm{PgC}$. The estimated value of total net carbon fixation in the present study was

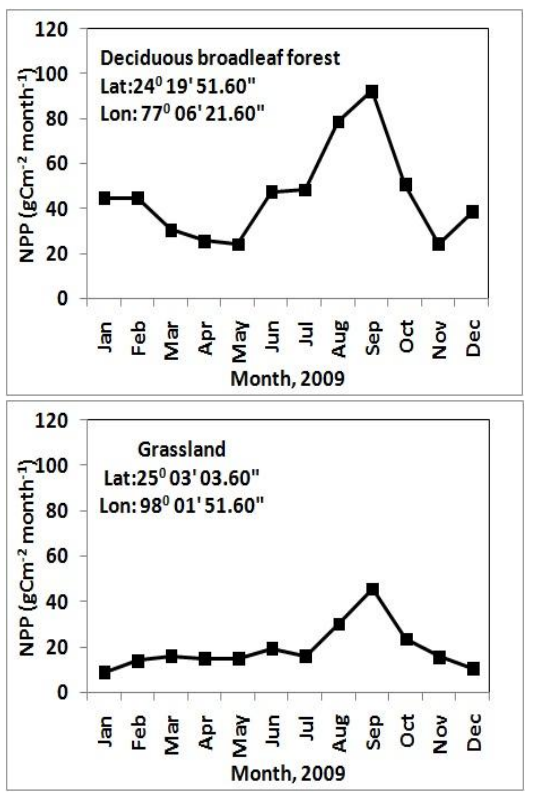

P for different vegetation types

comparable to that of earlier estimates for India by Chhabra and Dadhwal (2004). They reported net carbon fixation of $2.18 \mathrm{PgC}$. A recent work by Singh et al. (2011) used NOAA-AVHRR satellite data and the GLOPEM model for 1981-2000 and obtained values between 3.56 (1983) and 4.57 PgC (1998), respectively. More recent longterm studies by Nayak et al. (2012) and Bala et al. (2013) using NOAA AVHRR NDVI data and CASA model for the study period 1982 to 2006 reported $1.42 \mathrm{PgC}$ and $0.83 \mathrm{PgC}$ net carbon fixation over India.

Table 2. Agreement analysis between MODIS NPP and INSAT NPP

\begin{tabular}{lrrrrrrrr}
\hline & EBF & DBF & MF & CS & OS & GRA & CRO & CRO/NVM \\
\hline N & 1007 & 1039 & 1320 & 471 & 625 & 377 & 841 & 7103 \\
INSAT NPP (T) & 1001.25 & 867.23 & 976.33 & 680.47 & 358.14 & 523.82 & 640.87 & 594.48 \\
MODIS NPP (C) & 702.62 & 613.60 & 989.69 & 615.08 & 241.12 & 520.06 & 675.51 & 513.17 \\
Difference (C-T) & 298.62 & 253.63 & 13.36 & 65.39 & 117.02 & 3.76 & 34.63 & 81.30 \\
$\mathrm{~d}$ & 0.96 & 0.63 & 0.61 & 0.68 & 0.87 & 0.92 & 0.99 & 0.78 \\
RMSE $\left(\mathrm{gC} \mathrm{m}^{-2}\right.$ month $^{-1}$ ) & 339.42 & 346 & 290 & 158.4 & 136.3 & 113.2 & 114.7 & 133.95 \\
\hline
\end{tabular}

4.3 Comparison INSAT NPP with MODIS NPP

INSAT derived annual NPP values compared with MODIS NPP over different vegetation types (EBF, DBF, $\mathrm{MF}$, CS, OS, GRA, CRO, CRO/NVM) are shown in Table 2 with quantitative assessment of agreement using root mean square error (RMSE) and Willmott's index of agreement (d).

INSAT NPP simulated from the improved CASA ecosystem model was consistent with NPP fluxes obtained from MODIS. Mean INSAT NPP varied from $358.14 \mathrm{gC} \mathrm{m}^{-2} \mathrm{yr}^{-1}$ (OS) to $1001.25 \mathrm{gC} \mathrm{m}^{-2} \mathrm{yr}^{-1}$ (EBF) whereas, mean MODIS NPP ranged from $241.12 \mathrm{gC} \mathrm{m}^{-2}$ $\mathrm{yr}^{-1}$ (OS) to $989.69 \mathrm{gC} \mathrm{m}^{-2} \mathrm{yr}^{-1}$ (MF). INSAT NPP overestimates by MODIS NPP over all the vegetation

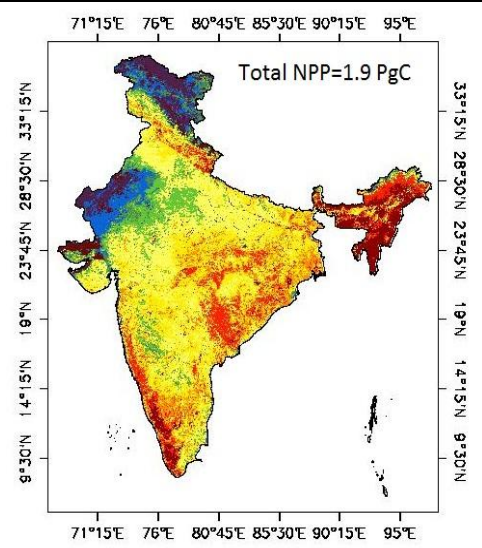
types except in MF and CRO. Significant difference between both the data sets was observed in MF with the Willmott's index of agreement (d) 0.61 . 


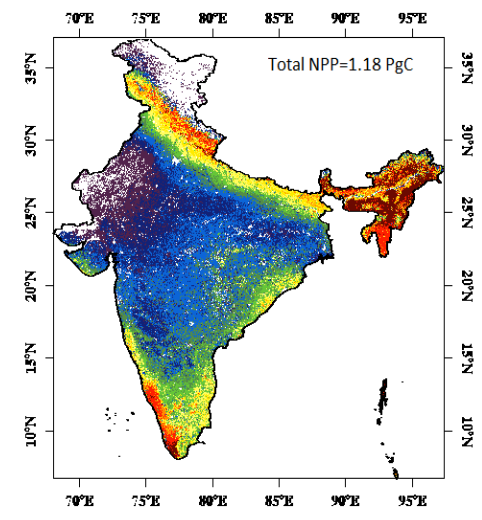

Net Primary Productivity $\left(\mathrm{g} \mathrm{C} \mathrm{m}^{-2}\right.$ year $\left.^{-1}\right)$

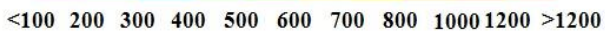

Figure 6 Spatial distribution of annual NPP in India Whereas, good agreement between both the data sets was observed in OSH with the Willmott's index of agreement (d) 0.99. The difference between INSAT NPP and MODIS NPP was mainly due to errors in pixel registration, model estimates and difference in scales when comparing $1 \mathrm{~km}$ MODIS NPP with the $8-\mathrm{km}$ INSAT NPP estimates. Spatial pattern of both the data sets matches evidently over North-eastern, Western Ghats and over Himalayan regions. Whereas, MODIS NPP underestimates considerably by INSAT NPP over most parts of the country including forest regions of Madhya Pradesh, Orissa and Chhattisgarh. Overall, INSAT NPP overestimates MODIS NPP product by $0.72 \mathrm{PgC}$ over Indian subcontinent.

\section{CONCLUSION AND FUTURE DIRECTION}

In the present study, an effort was made to estimate monthly Net Primary Productivity over Indian subcontinent using geostationary INSAT-3A CCD data and improved CASA ecosystem model for the study period 2009. Monthly NPP was generated at $8 \mathrm{~km}$ spatial resolution and tested the data through generating growth profiles of different vegetation types in the country. The NPP follows characteristic growth profiles of most of the vegetation types in the country. Spatial NPP pattern and net carbon fixation obtained by INSAT was compared with MODIS NPP product. There was a good agreement between both the data set over different ecosystems except mixed forest and closed Shrubland. Overall we estimated 1.9 PgC fixations by different ecosystem in the country. But the number was relatively higher $(0.72 \mathrm{PgC})$ than MODIS NPP.

\section{ACKNOWLEDGMENT}

This research was carried out under ISRO-GBP Geosphere Biosphere Programme, Energy and Mass Exchange in Vegetation System. Authors gratefully acknowledge Shri. A. S. Kiran Kumar, Director, SAC. Authors (RPS, SKG \& RP) are grateful to Dr. Pradeep Pal, Deputy Director EPSA and Dr. Prakash Chauhan, Group Head, BPSG/SAC for their suggestions and encouragement. One of the authors (Sheshakumar Goroshi) wishes to acknowledge the grant of fellowship by SAC. The authors thank NOAA, MODIS, CRU and MERRA for providing data sets for analysis.

\section{REFERENCES}

Bala, G., Joshi, J., Chaturvedi, R.K., Gangamani, H.V., Hashimoto, H., Nemani, R., 2013. Trends and Variability of AVHRR-Derived NPP in India. Remote Sensing. 5(2):810-829.

Boegh, E., Soegaard, H., Broge, N., Hasager, C. B., Jensen, N. O., \& Schelde, K., et al. (2002). Airborne multispectral data for quantifying leaf area index, nitrogen concentration, and photosynthetic efficiency in agriculture. Remote Sensing of Environment, 81, 179193.

Bonan, G.B., (1995). Land-atmosphere CO2 exchange simulated by a land surface process model coupled to an atmospheric general circulation model. Journal of Geophysical Research. 100: doi: 10.1029/94JD02961, issn: 0148-0227.

Bonan, G.B., (2008). Forests and Climate Change: Forcings, Feedbacks, and the Climate Benefits of Forests. Science, 320, 1444-1449.

Cao, M., Prince, S.D., Small, J., Goetz, S.J., (2004). Remotely sensed inter-annual variations and trends in terrestrial net primary productivity 1981-2000. Ecosystems. 7,233-42.

Chhabra, A and Dadhwal, V. K., 2004. Estimating terrestrial net primary productivity over India. Current Science, 86(2), 269-271.

Goward, Samuel N., and Stephen D. Prince. (1995) Transient Effects of Climate on Vegetation Dynamics: Satellite Observations." Journal of Biogeography 22.2/3: 549.

Gower, S. T., Kucharik, C. J., \& Norman, J. M. (1999). Direct and indirect estimation of leaf area index, fAPAR and net primary production of terrestrial ecosystems. Remote Sensing of Environment, 70, 29-51.

Grosso, D.S., Parton, W., Stohlgren, T., Zheng, D., Bachelet, D., Prince, S., Hibbard, K. and Olson, R., (2008). Global potential net primary production predicted from vegetation class, precipitation and temperature, Ecology, 89, 2117-2126.

Hicke, J. A., (2006). NCEP and GISS solar radiation data sets available for ecosystem modeling: description, differences, and impacts on net primary production. Global Biogeochemical Cycles, 19, pp. 1-18.

Kumar, M., Monteith, J.L., (1981). Remote sensing of crop growth, In: Smith, H., (eds.), Plants and Daylight Spectrum. Academic Press, New York. 133-144.

Law, B. E., Waring, R. H., (1994). Remote sensing of leaf area index and radiation intercepted by understory vegetation. Ecological Applications. 4, 272-279. 
Leith, H., (1975). Modeling the primary productivity of the world. In: Primary Productivity of the Biosphere $(\mathrm{H}$. Leith and R. H. Whittaker, Eds.), Springer-Verlag, Berlin and New York. pp. 237-263.

Liu, J., Chen, J. M., Cihlar, J., Park, W.M., (1997). A process-based boreal ecosystem productivity simulator using remote sensing inputs. Remote Sensing of Environment. 62, 58-175.

Nayak, R.K., Patel, N.R., Dadhwal, V.K., 2013. Interannual variability and climate control of terrestrial net primary productivity over India. Int. J. Climatol. 33(1):132-142

Peng, S.L., Guo, Z.H. and Wang, B.S., 2000. Use of GIS and RS to estimate the light utilization efficiency of the vegetation in Guangdong, China.

Potter, C.S., Randerson, J.T., Field, C.B., Matson, P.A., Vitousek, P.M., Mooney, H.A. And Klooster, S.A., 1993 Terrestrial ecosystem production: a process model based on global satellite and surface data. Global Biogeochemical Cycles, 7, pp. 811-841.

Ruimy, A. And Saugier, B., 1994, Methodology for the estimation of terrestrial net primary production from remotely sensed data. Journal of Geophysical Research, 97,pp. 18515-18521.

Running, S.W., Nemani, R.R., Peterson, D.L., Band, L.E. Potts, D.F., Pierce, L.L., Spanner, M.A., (1989). Mapping regional forest evapotranspiration and photosynthesis by coupling satellite data with ecosystem simulation. Ecology. 70,1090-1101

Sellers, P. J., Berry, J. A., Collatz, G. J., Field, C. B., \& Hall, F. G. (1992). Canopy reflectance, photosynthesis, and transpiration: III. A reanalysis using improved leaf models and a new canopy integration scheme. Remote Sensing of Environment, 42, 187- 216.

Sellers, P.J., (1985). Canopy reflectance, photosynthesis and transpiration. Int. J. Remote Sens.. 6, 1335-1372.

Singh, R.P.; Rovshan, S.; Goroshi, S.K.; Panigrahy, S.; Parihar, J.S., 2011. Spatial and temporal variability of Net Primary Productivity (NPP) over terrestrial biosphere of India using NOAA-AVHRR based GloPEM model. J. Ind. Soc. Remote Sens. 2011, 39, 345-353.

Yu, D., Shi, P., Shao, H., Zhu, W., Pan, Y., (2009). Modelling net primary productivity of terrestrial ecosystems in East Asia based on an improved CASA ecosystem model. I. J. of Remote Sensing. 30: 18, 48514866. 